\title{
Secretion of Pepsins and Hydrogen Ions in the Stomach of Children undergoing Cardiac Surgery
}

\author{
V. WALKER ${ }^{(27)}$ AND W. H. TAYLOR \\ Department of Chemical Pathology, Duncan Building, Royal Liverpool Hospital. Prescot Street, Liverpool L7 $8 X W$ \\ England
}

\section{Summary}

Gastric juice was collected from 27 children for 9 to $21 \mathrm{hr}$ following cardiac surgery, from 4 further children during and following cardiac surgery, and from 3 children who had not undergone surgery. Each sample was analyzed for hydrogen ion and pepsin content. The $\mathrm{pH}$ of the postoperative secretions from 26 patients was 1.25 to 5.30 , and the mean hydrogen ion concentration was $60.1 \mathrm{mmol} /$ liter (range, 21.5 to $119.3 \mathrm{mmol} / \mathrm{liter}$ ). The mean peptic activity $(83.0$ units $/ \mathrm{ml}$; range, 42.4 to 158.4 units $/ \mathrm{ml})$ was not age related and was significantly higher than that of the basal and pentagastrin-stimulated secretion and similar to that of vagally stimulated secretion of adults with peptic ulcer. The pepsin:hydrogen ion and pepsin 1:total pepsin ratios also resembled those of vagally stimulated secretion. During the first $90 \mathrm{~min}$ of cardiac surgery, the $\mathrm{pH}$ of aspirated gastric juice was 1.40 to 4.90 , the hydrogen ion concentration was 15.8 to $72.3 \mathrm{mmol} / \mathrm{liter}$, peptic activity was 39.2 to 164.0 units $/ \mathrm{ml}$ (mean, 97.2 units $/ \mathrm{ml}$ ). Pepsin 1 was present in all samples. Aspirates from 3 unoperated children had low total peptic activity and only trace amounts of pepsin 1. Children from the age of 5.5 months thus have the capacity to secrete all the major pepsins, including pepsin 1 . The findings suggest that vagal stimulation of gastric secretion was occurring during the postoperative period.

\section{Speculation}

It seems likely that the high total pepsin and pepsin 1 concentrations of children's gastric juice, under conditions of unusual stress, arise from vagal stimulation of the gastric chief cells. The resulting gastric environment is similar in many ways to that in chronic peptic ulcer in the adult and is conducive to acute peptic ulceration if one accepts the hypothesis that excess pepsins and pepsin 1 play a part in the pathogenesis of both acute and chronic peptic ulceration.

Children develop both acute and chronic peptic ulceration, and the incidence is now known to be greater than was formerly believed (7). Because results of gastric analyses are difficult to interpret in the pediatric age group (21), such investigations are rarely carried out, so that there are few reports of the normal peptic activity of children's gastric juice $(1,19)$ or of the nature of the pepsins secreted (5). It is now established that the adult man secretes at least 5 pepsins, and these have been numbered 1, 2, 3a, 3 , and 5 in order of decreasing mobility on agar gel electrophoresis (9). Pepsin 1 is secreted in greater concentration in response to histamine by adults with chronic peptic ulceration than by normal adults (20). The etiological significance of this observation requires further investigation. It is clearly relevant to any theory that implicates a particular pepsin in the ulcerogenic process to establish whether children have the capacity to secrete this pepsin and if so, whether the pepsin is secreted in high concentrations in those conditions known to predispose to ulceration.
During the period of 1974-1975, to monitor and therefore replace electrolyte losses following cardiac surgery, the anesthetists of the Royal Liverpool Children's Hospital routinely aspirated the gastric secretion of children during the early postoperative period. This provided a unique opportunity to study the gastric secretion of children, albeit under unusual and highly stressful conditions. Acute peptic ulceration has been reported as a complication of cardiac surgery $(4,10)$. The pepsin secretion of these children was compared with the basal, pentagastrin-, and vagally stimulated secretion of adults who had chronic peptic ulceration in the absence of similar reference values for normal healthy adults and for normal children.

\section{PATIENTS AND METHODS}

Gastric juice was aspirated via nasogastric tube from: (1) 27 children, aged 9 months to 13.5 years, during the first 9 to $21 \mathrm{hr}$ (mean, $18 \mathrm{hr}$ ) following cardiac surgery using cardiopulmonary by-pass. Gastric juice was collected primarily to assist control of electrolyte balance, and continuous aspiration was not practicable. The nasogastric tube was passed into the stomach at the end of surgery. The tube drained freely into a sterile bag, and residual gastric contents were removed using a syringe at two hourly intervals or more often if gastric dilation was suspected. Anesthesia was not reversed at the end of operation, respiration being maintained by intermittent positive pressure ventilation in the recovery ward until spontaneous respiration resumed. The drugs used most frequently postoperatively were benzylpenicillin, streptomycin, morphine, tubocurarine, digoxin, hydrocortisone, and pancuronium bromide. Four patients received chlorpromazine. All drugs were administered parenterally; (2) four children, aged 7 to 15 years, during cardiac surgery itself, using cardiopulmonary bypass, and for 16 to $20 \mathrm{hr}$ postoperatively. A nasogastric tube was passed into the stomach immediately after induction of anesthesia. Gastric secretion was aspirated at intervals throughout the operation and then two hourly postoperatively; (3) three children who had not undergone cardiac surgery; (4) eight adults (with intact vagi) with chronic peptic ulcer [six had duodenal ulcers (DU) and two gastric ulcers (GU)] for $90 \mathrm{~min}$ (seven patients) and $120 \mathrm{~min}$ (one patient) following IV soluble insulin $(0.15$ units $/ \mathrm{kg}$ body weight), 25 adults with chronic peptic ulcer ( 12 had D.U. and 13 GU) for $60 \mathrm{~min}$ following IM pentagastrin, or $90 \mathrm{~min}$ following SC pentagastrin $(6 \mu \mathrm{g} / \mathrm{kg}$ ). Of these 33 patients, only 23 (13 with DU and 10 with GU) had acid basal secretions in which pepsin could be studied electrophoretically. Gastric juice was collected over 15-min periods.

\section{DETERMINATION OF PROTEOLYTIC ACTIVITY}

Proteolytic activity of gastric juice was determined using a modification (23) of the method of Anson and Mirsky (2). One pepsin unit is arbitrarily defined as that amount of peptic activity which releases tyrosine and tyrosine-containing peptides from 
bovine hemoglobin colorimetrically equivalent to $1 \mathrm{mg}$ standard tyrosine under the conditions of assay.

\section{AGAR GEL ELECTROPHORESIS AND SEMIQUANTITATION OF PEPSIN 1}

Gastric juice samples, diluted in $0.001 \mathrm{M}$ hydrochloric acid, were examined by agar gel electrophoresis at $\mathrm{pH} 5.0$ as described by Etherington and Taylor (9), with the modifications of Walker and Taylor (23). With this method, the agar gels are incubated after electrophoresis in a solution of $3.3 \mathrm{~g} /$ liter human globin $(\mathrm{pH}$ $2.0)$ for $1.5 \mathrm{hr}$ at $37^{\circ} \mathrm{C}$. On subsequent staining with Ponceau "S", areas of proteolytic activity corresponding to the pepsins appear colorless against a red background. Negative photographs of the dried gels using a standard office copier (Dalcopier; W.A. Goddard, Manchester 12, United Kingdom) were obtained. Pepsin 3, always the most abundant pepsin, was allocated a grade of ++++ or +++ according to the intensity of proteolytic digestion. By reference to this zone and to a standard porcine pepsin marker. pepsin 1 was assigned a grade from 0 , for no activity to ++++ , for maximal activity. Two observers graded the pepsins independently. A "trace" of pepsin I was thus equivalent to approximately $10.5 \mu \mathrm{g}$ of porcine pepsin per $\mathrm{ml}$ of undiluted gastric juice, and ,,++++++ , and ++++ were equivalent to $22.5,60,250$, and $750 \mu \mathrm{g} / \mathrm{ml}$, respectively.

\section{HYDROGEN ION CONCENTRATION OF GASTRIC JUICE}

One $\mathrm{ml}$ volumes of gastric juice were titrated potentiometrically using a Titrator II (Radiometer Co.. Copenhagen, Denmark) with $0.1 \mathrm{M}$ sodium hydroxide to an endpoint of $\mathrm{pH} 7.4$.

\section{RELATIONSHIP OF PEPSIN I TO "TOTAL" PEPTIC ACTIVITY PER ML}

The results for all the $15 \mathrm{~min}$ gastric juice samples from the patients with peptic ulcer collected basally, following pentagastrin, and following insulin, and for those of the children following cardiac surgery were, for each condition of stimulation, grouped according to pepsin 1 grade. The mean peptic activity \pm S.E. (units/ml) was calculated for all samples having the same grade.

\section{RESULTS}

Gastric secretion was collected at two hourly intervals for 9 to $21 \mathrm{hr}$ postoperatively (mean, $18 \mathrm{hr}$ ), and the total volumes of the collections ranged from 10 to $300 \mathrm{ml}$ (mean, $88 \mathrm{ml}$ ).

The results of the analyses of the gastric aspirates are presented in Table 1 . When the data were analyzed, the results obtained on the aspirate ( $\mathrm{pH} \mathrm{6.3)} \mathrm{from} \mathrm{a} \mathrm{9-month-old} \mathrm{male} \mathrm{(patient} \mathrm{1)} \mathrm{are}$ excluded because the pepsinogens were shown to be activated incompletely on electrophoresis. However, trace of pepsin 1 was present (Fig. 1 a). The total peptic activity $(24.4$ units $/ \mathrm{ml})$ and the hydrogen ion concentration (11.3 mmoles/liter), were the lowest values observed in the study. The results for the four children for whom gastric secretion was studied during and following cardiac surgery (patients 28 to 31 ) are considered separately from those of the 26 patients (patients 2 to 27 ) whose gastric aspiration commenced at the end of surgery.

\section{HYDROGEN ION CONTENT}

The $\mathrm{pH}$ of the 26 aspirates from patients 2 to 27 ranged from 1.25 to 5.30 , and the mean secreted hydrogen ion concentration, as measured by the titratable acidity, was 60.1 mmoles/liter (range, 21.5 to $119.3 \mathrm{mmoles} / \mathrm{liter}$ ). This is a higher concentration than that found by Baron (3) for the basal secretion of normal adult men ( 0 to $71 \mathrm{mmoles} / \mathrm{liter}$, mean, 29.8) and normal adult women (0 to 54 mmoles/liter mean, 20.3).

\section{PEPTIC ACTIVITY}

The mean peptic activity of the 26 aspirates was 83.0 units $/ \mathrm{ml}$ of gastric juice (range 42.4 to 158.4 units/ml). Peptic activity per $\mathrm{ml}$ was not age related (Table 1 ). The mean peptic activity per $\mathrm{ml}$ was: (1) significantly higher than that of the basal secretion of 23 adults with chronic peptic ulceration $(29.2$ units $/ \mathrm{ml} ; P<0.001 ; n$ $=47$ ): (2) significantly higher than the mean highest activity per $\mathrm{ml}(42.0 \mathrm{units} / \mathrm{ml})$ secreted by 25 adults with chronic peptic ulcer in response to pentagastrin $(P<0.001 ; n=49)$; and (3) not significantly different from the mean highest peptic activity per $\mathrm{ml}$ of the secretions of eight adults with peptic ulceration in response to vagal stimulation by insulin hypoglycaemia $(81.8$ units $/ \mathrm{ml} ; P>0.9 ; n=32$ ) (Table 2).

THE RATIO OF THE PEPTIC ACTIVITY TO THE SECRETED HYDROGEN ION CONCENTRATION

The ratio of secreted pepsin to secreted hydrogen ion has been used as a means of assessing the effects of different gastric stimuli on the chief and parietal cells $(6,8,14)$. For each sample, a ratio was calculated of peptic activity (units/liter) to secreted hydrogen ion concentration (mmoles/liter). The mean ratio for 26 children was 1599 (range, 473 to 4000 ), the ratio being less than 1000 in $15.4 \%$ of the group (Table 2). This mean value was not significantly different from the mean highest ratio of 1634 of eight patients with peptic ulceration following insulin $(P>0.9 ; n=32)$, but was significantly greater than the mean highest ratio (1092) of 25 patients with peptic ulceration in response to pentagastrin $(P$ $<0.05 ; n=49$ ). When stimulated by insulin and pentagastrin, 25.0 and $60.0 \%$ of the gastric juices, respectively, had ratios of less than 1000 .

\section{PEPSIN I SECRETION}

Electrophoretograms were obtained for 24 children. Representative samples are shown in Figure $1 a$. Excluding patient 1 , the remaining 23 children (aged 2 to 13.5 years) all secreted + or more pepsin 1, with 16 children secreting amounts graded ++ or over (Table 1). The incidence of secretion of pepsin 1 in the higher concentrations $(++$ or over) may be compared with that among adults with chronic peptic ulceration (Table 3 ): eight of 23 , studied under basal conditions $(P<0.02): 18$ of 25 in response to pentagastrin $(P>0.8)$; and seven of eight in response to insulin $(P>$ $0.5)$. Pepsin 1 secretion by the children was not related to age (Table 1), but correlated well with the total peptic activity of the gastric juice (units/ml); those aspirates having the highest activity per ml contained most pepsin l. For comparison, electrophoretograms are shown (Fig. $1 b$ ) of gastric juice aspirated from three children, aged 5.5 months, 8 years, and 11 years who did not have cardiac surgery. Both the pepsin concentration and the amount of pepsin 1 are lower than in the other 31 children.

THE RELATIONSHIP OF PEPSIN I SECRETION TO PEPTIC ACTIVITY/ML OF GASTRIC JUICE

It is apparent (Fig. 2) that the relationship of pepsin 1 concentration to peptic activity/ml of gastric secretion in the group of children who had cardiac surgery was similar to that of the secretion of adults with peptic ulceration, in response to vagal stimulation and was unlike that under basal conditions or following pentagastrin.

\section{THE GASTRIC SECRETION OF 4 CHILDREN DURING CARDIAC} SURGERY (TABLE 1)

The total volume of gastric juice collected during surgery ranged from 6 to $25 \mathrm{ml} ; 2.5$ to $8.0 \mathrm{ml}$ of this was aspirated immediately after induction of anesthesia, and most of the remainder was aspirated during the first $90 \mathrm{~min}$ of surgery (the operations lasted 3 to $4 \mathrm{hr}$ ). The secretion after $90 \mathrm{~min}$ was negligible. The $\mathrm{pH}$ of aspirates ranged from 1.40 to 4.90 , and the hydrogen ion concentration was from 15.8 to $72.3 \mathrm{mmoles} / \mathrm{liter}$ (mean, 31.9). The lowest $\mathrm{pH}$ was recorded in gastric juice secreted by patient 28 after he developed a hypersensitivity reaction with a "histamine flare" of the skin during induction of anesthesia. The hydrogen ion concentration of this sample was 72.3 mmoles/liter. The mean 
SECRETION OF PEPSINS AND HYDROGEN IONS

Table 1. Gastric aspirates from 27 children following cardiac surgery, and from 4 children during and following cardiac surgery

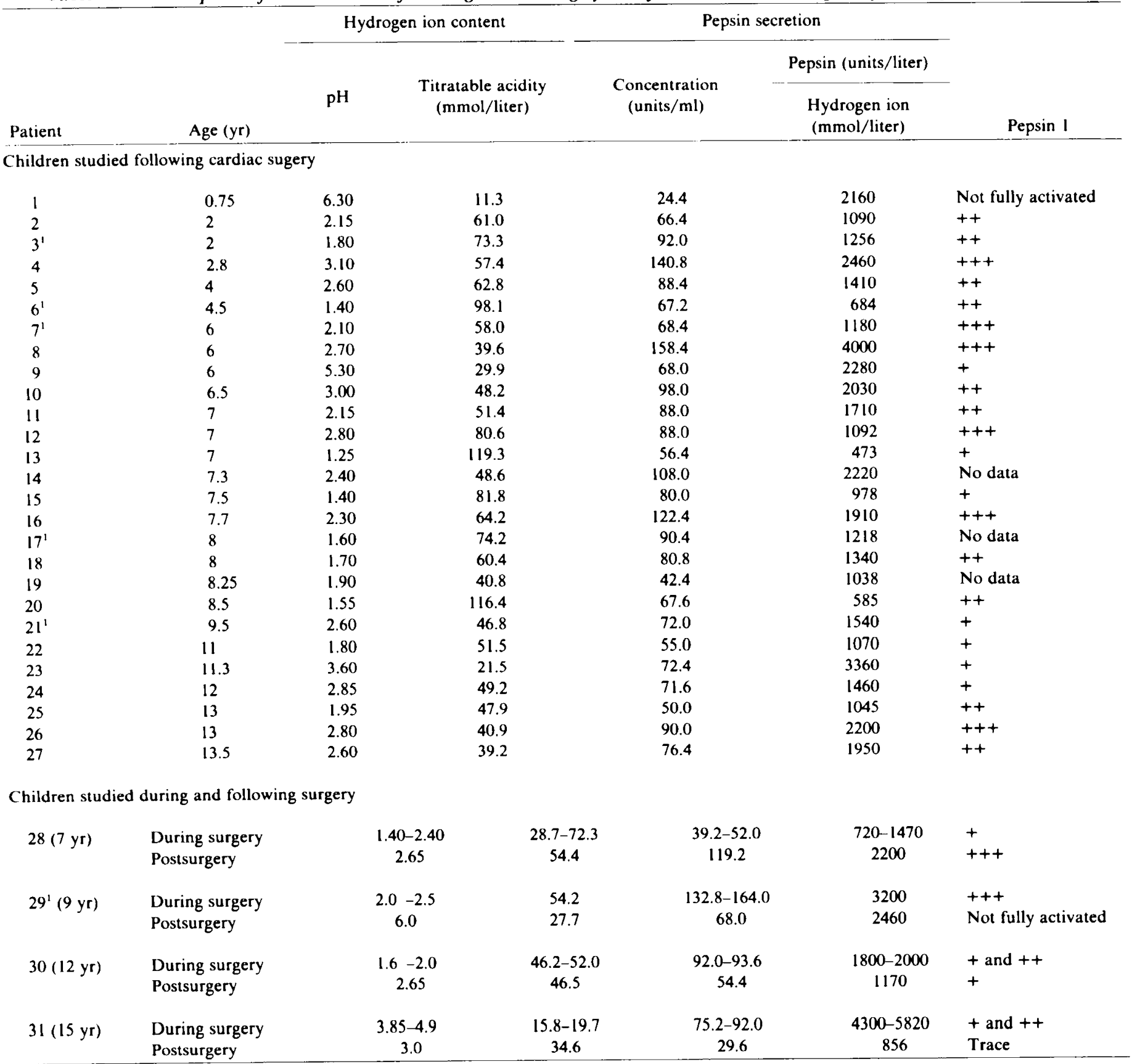

'Samples containing blood.

Table 2. Pepsin content of gastric juice aspirated from children following cardiac surgery compared with that of adults with chronic peptic ulceration basally, and following insulin and pentagastrin stimulation ${ }^{1}$

\begin{tabular}{|c|c|c|c|c|c|}
\hline \multirow[b]{3}{*}{ Stimulus (no. of patients) } & \multirow{2}{*}{\multicolumn{2}{|c|}{ Peptic activity (units/ml) }} & \multicolumn{2}{|c|}{ Pepsin (units/liter) } & \multirow[b]{3}{*}{$\%$ less than 1000} \\
\hline & & & \multicolumn{2}{|c|}{ Hydrogen ions (mmol/liter) } & \\
\hline & Mean & Range & Mean & Range & \\
\hline \multicolumn{6}{|l|}{ Children } \\
\hline Cardiac surgery (26) & 83.0 & $42.4-158.4$ & 1599 & $473-4000$ & 15.4 \\
\hline Adults with peptic ulcer basal (23) & 29.2 & $6.8-47.4$ & & & \\
\hline Pentagastrin $(25)$ & 42.0 & $24.0-78.0$ & 1092 & $140-3871$ & 60.0 \\
\hline Insulin (8) & 81.8 & $57.6-170.4$ & 1634 & $669-3200$ & 25.0 \\
\hline
\end{tabular}

${ }^{1}$ The highest observed peptic activity/ml and pepsin:hydrogen ratio for each adult following stimulation was used. 


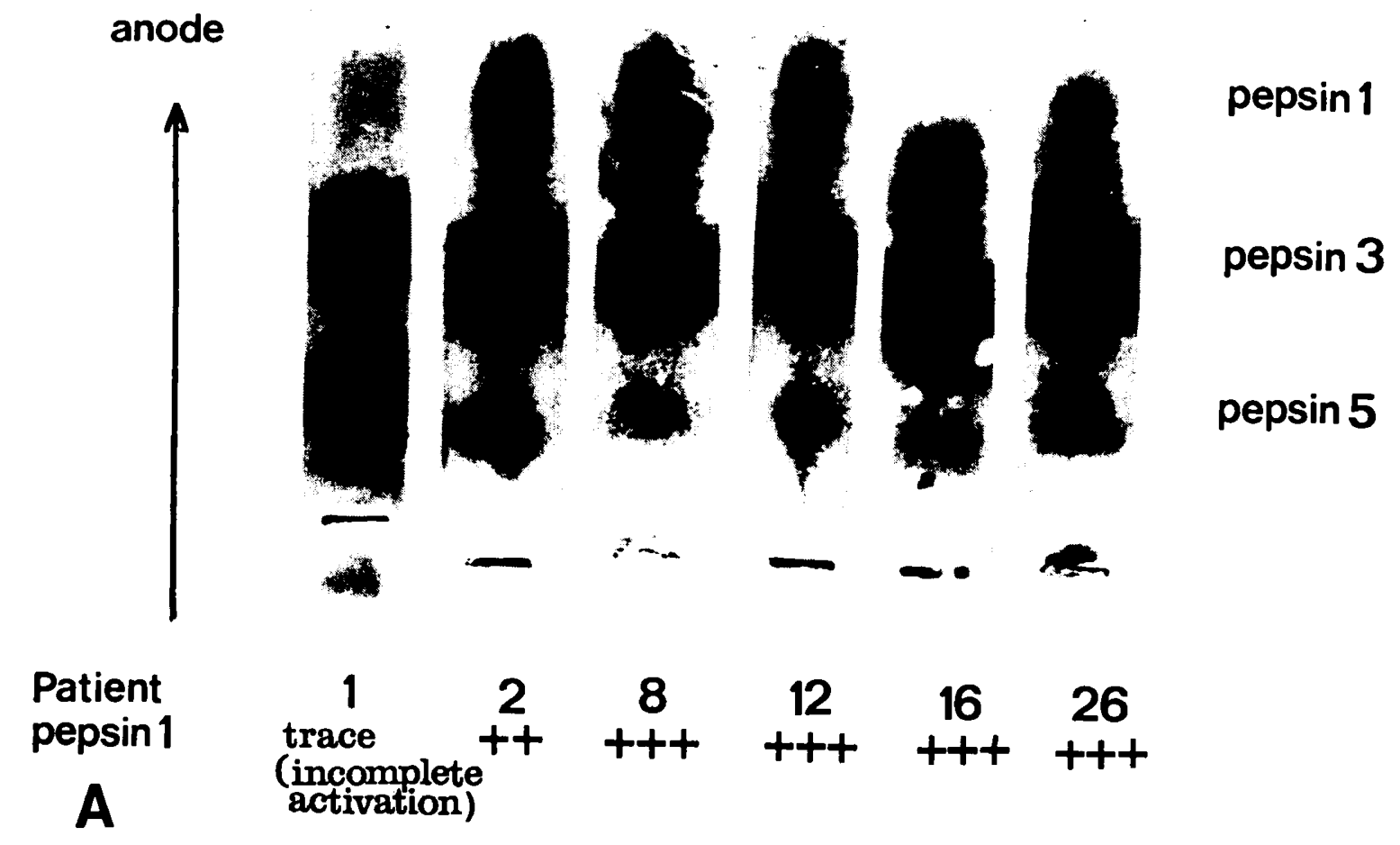

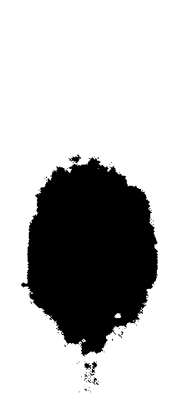

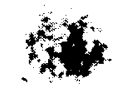

\section{Patient \\ pepsin 1}

B

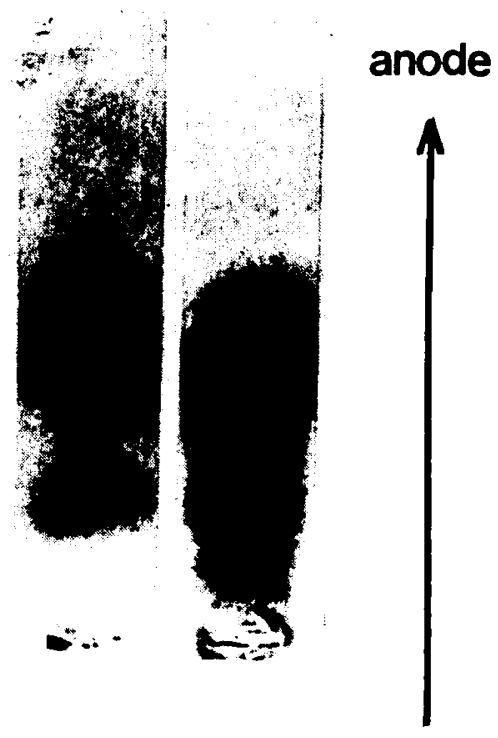

$33 \quad 34$

trace 0

Fig. 1. a, agar gel electrophoretograms of gastric aspirates from 6 children following cardiac surgery. The gastric juice from patient 1 was applied in a 1 in 5 dilution in $0.001 \mathrm{M}$ hydrochloric acid; from patient 2,1 in 10; from patient 8, 1 in 40; and from the other patients, 1 in 15 dilution. The pepsin 1 grades are shown. $b$, agar gel electrophoretograms of gastric aspirates from 3 unoperated children. Patient 32, 5.5-month-old conscious male. The sample ( $\mathrm{pH} 3.0$ ) was obtained during a milk feed via an IG tube. Electrophoresis of 1 in 15 dilution in $0.001 \mathrm{M}$ hydrochloric acid shows pepsin 1 in

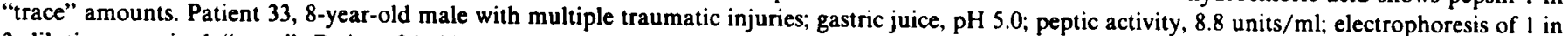
3 dilution; pepsin 1 "trace". Patient 34, 11 -year-old female unconscious following head injury; gastric juice, pH 5.5; peptic activity, 18.0 units/ml; electrophoresis of 1 -in-4 dilution; no pepsin 1 visualized but pepsinogens incompletely activated. 
Table 3. Pepsin 1 secretion by children following cardiac surgery and by adults with chronic peptic ulceration basally and following gastric stimulation

\begin{tabular}{|c|c|c|c|c|c|c|}
\hline \multirow[b]{3}{*}{ Patients } & \multicolumn{6}{|c|}{ Patients secreting pepsin 1} \\
\hline & \multicolumn{2}{|c|}{+ or more } & \multicolumn{2}{|c|}{++ or more } & \multicolumn{2}{|c|}{+++ or more } \\
\hline & No. & $\%$ & No. & $\%$ & No. & $\%$ \\
\hline Children following cardiac surgery $(23)^{1}$ & 23 & 100.0 & 16 & 69.6 & 6 & 26.1 \\
\hline Adults (peptic ulceration) basal conditions (23) & 20 & 87.0 & 8 & 34.8 & 0 & 0 \\
\hline Adults (peptic ulceration) pentagastrin (25) & 24 & 96.0 & 18 & 72.0 & 6 & 24.0 \\
\hline Adults (peptic ulceration) insulin hypoglycaemia (8) & 8 & 100.0 & 7 & 87.5 & 4 & 50.0 \\
\hline
\end{tabular}

'Numbers in parentheses, number of patients.

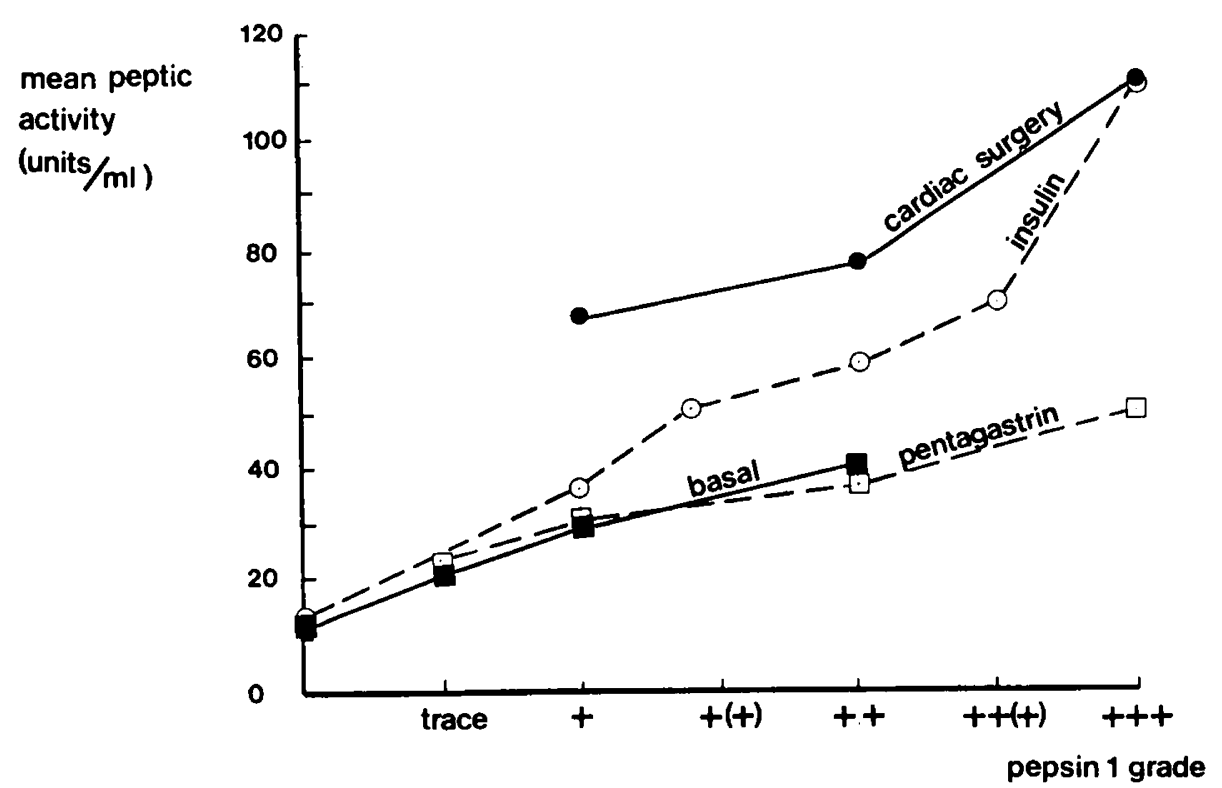

Fig. 2. The relationship between pepsin 1 and total peptic activity per ml of the gastric juice secreted by children following cardiac surgery ( compared with the gastric secretions of adults with chronic peptic ulceration. $\square$, basally; $\square$, in response to pentagastrin; $\bigcirc$, in response to insulin.

peptic activity per $\mathrm{ml}$ of 12 aspirates collected during surgery from the four children was 97.2 units/ml (range, 39.2 to 164.0 units/ml) and not significantly different from that of the postoperative samples. Pepsin 1 was present in all samples collected during surgery, three of the patients secreting ++ or more at some stage. Postoperatively, only patient 28 secreted high concentrations of pepsin 1; patients 30 and 31 secreted "+" and "trace."

\section{DISCUSSION}

The results indicate that children from the age of 5.5 months (the youngest studied) have the capacity to secrete all the major pepsins, and in particular, that they are able to secrete pepsin 1 , the "ulcer-associated" pepsin of adults. The physiologic and pharmacologic stresses during and after cardiac surgery with cardiopulmonary by-pass are great, and under these very abnormal conditions, the gastric juice collected contained high concentrations of pepsin when compared with the secretion of adults with chronic peptic ulceration. Pepsin 1 made a significant contribution to the total peptic activity, and in some samples was present in higher concentrations than was pepsin 5, giving the agar gel electrophoretograms a somewhat "top-heavy" appearance (Fig. 1a) because in adults pepsin 5 is usually more abundant than pepsin 1 .

It is apparent from the results of analyses of gastric juice from the three unoperated children that the nature of the gastric secretion in childhood is variable and that high total concentrations of the pepsins and of pepsin 1 are not a constant feature. From the limited information available $(1,19)$, high total pepsin concentrations have not been found in normal children up to 30 months of age. From the results of one study, it seems unlikely that normal children secrete large amounts of pepsin 1. Cathelineau (5) identified four zones of proteolytic activity by agar gel electrophoresis and by chromatography on DEAE-cellulose of histamine-stimulated gastric juice of normal children (age not stated) and of infants under three months of age; the most anodally migrating enzyme on electrophoresis, which is likely to be pepsin 1, was present in small concentration only.

There are several possible explanations for the findings of the present study. First, considering the generally low volumes of secretion collected postoperatively, there may have been a dissociation between the enzymic and aqueous components of the secretion. This explanation would account for the high total concentration of the pepsins observed, but not for the change in the relative proportions of the pepsins seen, with a more marked increase in pepsin 1. Because the gastric juice was aspirated at two hourly intervals only, a more likely explanation of the low volumes recovered is that some of the secreted juice drained from the stomach via the pylorus. Secondly, the effect of coincident therapy must be considered. Of the drugs which were used, tubocurarine may increase gastric secretion because of its histamine-releasing properties (17), but in man, histamine-stimulated gastric juice does not have a high pepsin content (16). Short-term administration of hydrocortisone does not stimulate gastric acid or pepsin secretion (15). None of the other drugs used is known to influence gastric secretion directly, although morphine and chlorpromazine, having an action on the central nervous system, might possibly have an indirect effect. Chlorpromazine was used in only four patients and could not have accounted for the findings in the majority of patients. Thirdly, Hirschowitz et al. (13) have demonstrated in man that the concentration of pepsinogen secreted in the gastric 
juice increased during hyperventilation up to $30 \%$ higher than is observed following insulin stimulation. A local stimulus to the peptic cells seemed to be operative. The children in the present study were maintained on intermittent positive pressure ventilation for a minimum of $2 \mathrm{hr}$ postoperatively and in some up to 21 $\mathrm{hr}$ and they may have been hyperventilated at times. Fourthly, blood was present in the gastric juice of six of the children studied, indicating that there had been some damage to the gastric mucosa. It is possible, therefore, that the high pepsin concentrations in the gastric juice of these and also of the other children might have been attributable to pepsin released from disintegrating peptic cells damaged, perhaps, by ischemia. This possibility cannot be excluded on the available evidence, although the observed hydrogen ion secretion is indicative of normal function of at least some mucosal (parietal) cells. A further indication that peptic cell disintegration was unlikely to be of major importance in the present study was that in those patients in whom we estimated serum pepsinogen levels (22) the values tended to fall postoperatively, whereas Hirschowitz (12) has shown that the serum pepsinogen level rises following gastric mucosal damage.

The remaining alternative is that there was an excessive endogenous stimulation of the gastric mucosa. From the pepsin:hydrogen ion ratio and the pepsin 1:total pepsin ratio, an increased vagal activity is more likely than is increased release of gastrin (which has actions on human gastric secretion similar to those of the synthetic agent pentagastrin). The vagus is the strongest stimulus of pepsin secretion in man (12) and in the cat stimulates secretion of the most anodally migrating pepsin (25). However, one or more of the other gastrointestinal hormones, such as secretin or motilin, known to stimulate pepsin secretion might conceivably have been responsible. Adrenocorticosteroids, whose secretion increases following cardiac surgery $(11,24)$ probably do not stimulate pepsin secretion directly $(15,18)$.

Whatever the cause of the high total pepsin and pepsin 1 concentrations in the children's gastric secretion following cardiac surgery, the findings indicate that the gastric environment has similarities with that of patients with peptic ulcer after insulin stimulation. Acute peptic ulceration may occur after cardiac surgery, and the possibility arises, as with chronic peptic ulcer in the adult, that the pepsins, and particularly pepsin 1 , could play a part in its pathogenesis.

\section{REFERENCES AND NOTES}

1. Agunod, M., Yamaguchi, N.. Lopez, R., Luhby, A. L., and Glass, G. B. J.: Correlative study of hydrochloric acid. pepsin, and intrinsic factor secretion in newborns and infants. Am. J. Dig. Dis., 14:400 (1969).

2. Anson. M. L., and Mirsky. A. E.: Estimation of pepsin with haemoglobin. J. Gen Physiol.. 16: 59 (1932).

3. Baron, J. H.: Studies of basal and peak acid output with an augmented histamine test. Gut. 4: 136 (1963).
4. Berkowitz. D., Wagner, B. M., and Uricchio, J. F.: Acute peptic ulceration following cardiac surgery. Ann. Intern. Med., 46: 1015 (1957).

5. Cathelineau, L.: Pepsins in gastric juice of infants and children. Acta Paediatr. Scand. (Abstract), 61: 497 (1972)

6. Cooke, A. R.: Acid and pepsin secretion in response to endogenous and exogenous cholinergic stimulation and pentapeptide. Aust. J. Exp. Biol. Med. Sci.. 47: 197 (1969).

7. Curci, M. R., Little K., Sieber, W. K., and Kiesewelter, W. B.: Peptic ulcer disease in childhood re-examined. J. Pediatr. Surg., 11: 329 (1976).

8. Elder, J., and Smith. I. S.: Gastric-acid output. pepsin output, and lean body mass in normal and duodenal ulcer subjects. Lancet, $I: 1000$ (1975).

9. Etherington D. J., and Taylor. W. H.: The pepsins of normal human gastric juice. Biochem. J., 113: 663 (1969)

10. Gilbert, J. W., and Morrow, A. G. Gastrointestinal bleeding after cardiovascular operations in children. Surgery, 47: 685 (1960).

11. Hasner. E., Buus, O., Rygg, I. H., and Therkelsen, F.: The adrenocortical activity in extracorporeal circulation. Acta Chir. Scand., 122: 235 (1961).

12. Hirschowitz, B. 1.: Secretion of pepsinogen. In: C. F. Code: Handbook of Physiology, Section 6. Volume 2. Chap. 50. pp. 839-918 (Washington. D. C.. 1967).

13. Hirschowitz, B. I., London, J. A., and Wiggins, H. S.: Stimulation of gastric pepsin secretion in man by hyperventilation and by diamox. J. Lab. Clin Med., 53: 577 (1959)

14. Hirschowitz. B. I., Schenker, S., and Boyett. J. D.: A highly active gastric secretagogue extracted from a metastasis of a Zollinger-Ellison tumour. Am. J. Dig. Dis., 8: 499 (1963).

15. Hirschowitz. B. 1.. Streeton, D. H. P., London. J.. and Pollard. H. M.: Effects of 8 hour intravenous infusions of ACTH and the adrenocortical steroids in normal man. I. Basal gastric secretion and plasma and urinary pepsinogen. J. Clin. Invest.. 36: 1171 (1957).

16. Ihre, B.: Human gastric secretion. Acta Med. Scand. Suppl.. 95: 9 (1938)

17. Lorenz, W.. Doenicke. A., Meyer, R.. Reimann, H. J.. Kushe, J., Barth, H. Geesing. H., Hutzel, M., and Weissenbacher, B.: Histamine release in man by propanidid and thiopentone: pharmacological effects and clinical consequences. Br. J. Anaesth., 44: 355 (1972).

18. Mirsky, I. A.: Physiologic, psychologic and social determinants in the etiology of duodenal ulcer. Am. J. Dig. Dis., 3: 285 (1958).

19. Rodbro, P., Krasilnikoff. P. A., and Bitsch. V.: Gastric secretion of pepsin in early childhood. Scand. J. Gastroenterol., 2: 257 (1967).

20. Taylor, W. H.: Pepsins of patients with peptic ulcer. Nature (Lond.), 227: 76 (1970).

21. Tudor, R. B.: Peptic ulceration in childhood. Pediatr. Clin. N. Am., 14: 109 (1967).

22. Walker, V.: Aspects of the pathophysiology of the pepsins. (M. D. Thesis, University of Liverpool, 1976).

23. Walker, $V$. and Taylor $W$. H.: Ovalbumin digestion by pepsins 1,3 and 5 . Biochem. J., 176 Part 2: 429 (1978).

24. Walker. W. F.: Adrenal response to cardiac surgery. Proc. Roy. Soc. Med., 1015 (1965).

25. Wright, C. L., Shaw, B., Sanders, D. J., and Reed, J. D.: Variation in the proportions of individual pepsins secreted by the cat in response to vagal stimulation and hypoglycaemia. Clin. Sci. Mol. Med., 48: 297 (1975).

26. The authors thank Dr. J. Shackleton and Dr. R. S. Jones of the Royal Liverpool Children's Hospital for access to their patients, Dr. G. J. Rees for the gastric aspirates obtained during and after cardiac surgery, and Dr. R. B. McConnell and his staff of the Gastroenterology Unit. Broadgreen Hospital, for gastric juice from patients with peptic ulceration.

27. Requests for reprints should be addressed to: Dr. V. Walker, South Laboratory and Pathology Block, Level D. Southampton General Hospital, Tremona Road. Southampton S09 4XY England.

28. Received for publication April 30, 1979

29. Accepted for publication December 20. 1979 